\title{
THE
}

\section{Comparing species and ecosystem-based estimates of fisheries yields}

John H. Steele

Dian J. Gifford

University of Rhode Island

Jeremy S. Collie

University of Rhode Island, jcollie@uri.edu

Follow this and additional works at: https://digitalcommons.uri.edu/gsofacpubs

Creative Commons License c) (i) $\Theta$

This work is licensed under a Creative Commons Attribution-Noncommercial-No Derivative Works 4.0 License.

\section{Citation/Publisher Attribution}

Steele, J. H., Gifford, D. J., \& Collie, J. S. (2011). Comparing species and ecosystem-based estimates of fisheries yields. Fisheries Research, 111(3), 139-144. doi: 10.1016/j.fishres.2011.07.009

Available at: https://doi.org/10.1016/j.fishres.2011.07.009

This Article is brought to you for free and open access by the Graduate School of Oceanography at DigitalCommons@URI. It has been accepted for inclusion in Graduate School of Oceanography Faculty Publications by an authorized administrator of DigitalCommons@URI. For more information, please contact digitalcommons-group@uri.edu. 


\title{
Does Clinician Continuity Over Two Brief Motivational Sessions Improve Outcomes in College Students?
}

\author{
Erica Eaton Short ${ }^{\mathrm{a}, \mathrm{b}}$, Anne Fernandez $^{\mathrm{c}}$, Brian Borsarid,a, John T.P. Hustad ${ }^{\mathrm{a}}$, and Mark \\ Wood ${ }^{\mathrm{c}, \mathrm{a}}$ \\ a Brown University, Center for Alcohol and Addiction Studies, Box G-S121-5 Providence, RI \\ 02903 \\ b Fielding Graduate University, 2112 Santa Barbara Street Santa Barbara, CA 93105 \\ c University of Rhode Island, Department of Psychology, Kingston, RI 02881 \\ ${ }^{d}$ Mental Health and Behavioral Sciences Service, Service Department of Veterans Affairs \\ Medical Center, 830 Chalkstone Avenue Providence, RI 02908
}

\begin{abstract}
Previous research has shown that Brief Motivational Interventions (BMIs) are an effective treatment approach for reducing college student alcohol use and associated negative consequences. The purpose of this study was to determine whether clinician continuity (having the same vs. a different clinician) across an initial BMI and follow-up booster session was related to differences in session satisfaction, self-reported alcohol use, and alcohol-related negative consequences. Participants included 358 undergraduate students who were part of a larger randomized clinical trial. Results revealed no significant differences in alcohol use and associated consequences at follow-up between participants who met with the same vs. a different clinician. Clinician continuity was not significantly related to intervention fidelity in terms of BMI consistent qualities, relevance of information presented, or session satisfaction. These findings suggest that clinician continuity across BMIs for college students is not related to participant satisfaction or intervention effectiveness, especially if the clinicians adhere to empirically supported techniques.
\end{abstract}

\section{Keywords}

College students; alcohol; brief motivational interviewing; booster session

\section{Introduction}

Brief Motivational Interventions (BMIs) are among the most effective treatments for reducing college student drinking, and have been associated with decreases in alcohol use and problems among freshmen, upper-class, and judicially-mandated students relative to control and 'treatment as usual' conditions (Larimer \& Cronce, 2002, 2007). BMIs incorporate Motivational Interviewing (MI; Miller \& Rollnick, 2002), a clinical style that is

\footnotetext{
(c) 2011 Elsevier Inc. All rights reserved.

Corresponding author: Erica Eaton Short, Center for Alcohol and Addiction Studies, Brown University, erica_eaton@brown.edu, PH: 401.273.7100 x6280.

Publisher's Disclaimer: This is a PDF file of an unedited manuscript that has been accepted for publication. As a service to our customers we are providing this early version of the manuscript. The manuscript will undergo copyediting, typesetting, and review of the resulting proof before it is published in its final citable form. Please note that during the production process errors may be discovered which could affect the content, and all legal disclaimers that apply to the journal pertain.
} 
empirically validated for use when treating substance abuse disorders (Burke, Arkowitz, \& Dunn, 2002; Dunn, Deroo, \& Rivara, 2001). MI focuses on creating a relationship of mutual understanding and support between the therapist and client and aims to elicit behavior change by decreasing ambivalence in a nonjudgmental and empathetic fashion (Miller \& Rollnick, 2002). MI is guided by four basic principles: expression of empathy, developing discrepancy, rolling with resistance, and supporting self-efficacy (Miller \& Rollnick, 2002).

Despite promising evidence demonstrating the efficacy of BMIs, there is a need to increase the impact and sustainability of BMI effects (Larimer \& Cronce, 2002, 2007). Follow- up BMIs (or 'booster' sessions) are one method that may enhance the durability of intervention effects (Collins et al., 2002). Booster sessions allow an opportunity for a client to have additional contact with a clinician, further discuss and reflect upon alcohol-related behavior, and explore any change or lack of change associated with alcohol consumption and related harm. Booster sessions also represent a method to provide continuity of care. Importantly, booster sessions provide an opportunity to reinforce positive behavioral change from the previous session and/or provide additional intervention when appropriate. Among adult problem drinkers, additional follow-up sessions can improve BMI outcomes (Longabaugh, et al., 2001) and increase participant satisfaction (Lee, et al., 2007). To date, these findings have not been replicated among mandated college students (Barnett, Murphy, Colby, \& Monti, 2007). Therefore, the use of a booster session coupled with a follow-up assessment is a potential way to sustain and increase BMI efficacy.

Overall, little is known about BMI session processes and subsequent effects on behavior change (Larimer \& Cronce, 2007). As a BMI with a booster session (or sessions) require more than one interaction with a clinician, a possible mechanism through which BMIs influence behavior is the client-therapist relationship across sessions. The link between the therapeutic relationship and client outcomes is well established (Grencavage \& Norcross, 1990; Horvath \& Bedi, 2002; Kazdin, 2005). For example, therapist attributes such as accurate empathy, affirmation, and understanding have been linked to the increased quality and strength of the therapeutic relationship (Ackerman \& Hilsenroth, 2003; Horvath \& Bedi, 2002). These clinical qualities are pivotal in cultivating a strong therapeutic relationship and consequently treatment outcomes. To date, over 2000 studies have supported that the therapeutic relationship predicts treatment outcome, and the better the alliance, the greater the change (Kazdin, 2005; Hovarth \& Bedi, 2002). In addition, one would assume that clinician continuity across therapeutic interactions would improve the therapist-client relationship, enhance therapeutic processes; and increases the likelihood of adaptive behavioral changes. However, this assumption remains untested in multi-session BMIs with college students.

The purpose of the current study was to examine whether clinician continuity (having the same vs. a different clinician) across the initial BMI and follow-up booster session was related to participant reports of BMI session satisfaction, relevance, and MI-consistent clinician behavior (rapport, empathy, and autonomy), as well as the participants' subsequent alcohol use, and alcohol-related negative consequences. To do so, we conducted a secondary analysis of a universal preventive intervention conducted as a randomized controlled trial $(\mathrm{RCT})$ which used a $2 \times 2$ factorial design to examine the individual and combined effects of two complementary interventions: a two-session BMI and a Parent Based Intervention (PBI; Wood et al., 2010). There were three treatment groups (BMI; PBI; BMI \& PBI) and an assessment-only control group. The BMI and PBI aimed to reduce the onset and magnitude of alcohol use and alcohol-related negative consequences among incoming college freshman. Findings indicated that effect sizes for the BMI and combined BMI-PBI conditions were larger at 22- months than 10- month post-baseline, but still small in magnitude (Cohen's $h=.22$ for alcohol use and 0.15 for consequences). Delayed 
intervention effects such as these are at odds with typically observed patterns of intervention decay (Hettema, Steele, \& Miller, 2005). A potential explanation is that the BMI booster session was especially useful for delaying the onset of heavy episodic drinking and consequences among those who had not yet initiated these behaviors. The current research was conducted to examine whether clinician continuity was related to treatment process factors that may have enhanced the efficacy of the BMI and/or follow up booster sessions.

\section{Materials and Methods}

\subsection{Parent Study}

The current study is a secondary analysis of a RCT of two interventions: 1) a BMI with booster and 2) a parent based intervention. The study examined the effectiveness of these interventions to reduce alcohol use and alcohol-related negative consequences among incoming college freshman (Wood et al., 2010). Findings indicated BMIs reduced alcoholrelated consequences and heavy episodic drinking at each of the follow-ups (10- and 22months post-baseline).

\subsection{Participants and Recruitment}

The parent study (Wood et al., 2010) was conducted at a mid-sized northeastern public university with an undergraduate population of roughly 11,000 students (56\% female, and 76\% White/Caucasian). All first-time incoming college freshmen who had submitted their university attendance deposit by May 1st were eligible to participate in the parent study. In total 1,537 students were assessed for eligibility, and 1,014 students were recruited across two successive academic years (See Figure 1 for attrition breakdown). Out of the 1,014 students successfully recruited, 4991 were randomized to the BMI condition (either BMIonly, $n=253$ or BMI + PBI, $n=249$ ), which is the focus of this study. In this study, participants in both the BMI-only condition and the BMI + PBI condition were combined to examine all those who completed a BMI. All other students were randomized to either a parent-based intervention or an assessment only control condition. Included in current analyses, were 358 of the 499 BMI participants (71.7\%) who attended both the BMI in the Fall of their freshman year and the booster session in the Spring of the freshman year. Twohundred eighty three $(56.7 \%)$ of participants in the BMI conditions provided session evaluation information used in the analysis of session process and satisfaction. All procedures were approved by the university Institutional Review Board.

\subsection{Intervention}

The BMI used in this study was modeled after the BASICS program developed at the University of Washington (Dimeff, Baer, Kivlahan, \& Marlatt, 1999). The first BMI took place in the Fall of the participant's freshman year and lasted approximately 45-60 minutes, and was administered in private on-campus project spaces where students met in-person with trained clinicians. The feedback for the fall BMI was generated from an online survey which took place within two weeks of the scheduled appointment. The sessions were tailored according to drinking status (abstainer, current drinker) and were guided by computer-generated personalized feedback collected prior to each session. Drinkers received feedback on their alcohol use, alcohol-related beliefs and behavior, normative and educational information about alcohol, and strategies for reducing alcohol-related negative consequences. Abstainers received feedback regarding abstinence as a safe and healthy

\footnotetext{
${ }^{1}$ Three participants were administratively dropped from the study following randomization. One student died for reasons unrelated to the study and two began working at the data collection center conducting assessments for the study.
} 
choice, their alcohol-related beliefs and second-hand experiences related to alcohol, normative and educational information, and strategies to maintain abstinence.

The booster session was conducted the following spring and lasted 20-30 minutes. The feedback for the booster session was generated from the 10 month follow-up assessment. Efforts were made to schedule all students to meet with the same clinician for the BMI and booster session. However, this was not always possible due to scheduling conflicts. Scheduling flexibility was crucial in retaining completion rates for the study, and therefore many students saw different clinicians for the booster session. In addition, one clinician left the project prior to the booster intervention and one interventionist was added for the booster sessions only. Therefore, two hundred fifty one participants saw the same clinician $(70.1 \%)$ and 107 saw a different clinician at the booster session (29.9\%).

Project interventionists included 16 graduate-level psychology students (14 females; B.A. or higher). Clinicians received training for the initial BMI and booster session from the third author (B. Borsari), a licensed clinical psychologist who has extensive training and experience in MI methodology and research (e.g., Borsari \& Carey, 2000; Borsari \& Carey, 2005; Borsari, Murphy, \& Carey, 2009). Training involved two full days in which clinicians were required to demonstrate their abilities during a supervised role-play prior to conducting BMI sessions. Group supervision meetings (1.5 hours) were conducted weekly during BMI administration periods, and fidelity checks were carried out regularly throughout the study. Every week supervisors reviewed two randomly selected audiotapes and provided written feedback to interventionists regarding the use of BMI techniques and adherence to protocol. Clinicians were informally provided feedback using the Motivational Interviewing Skills Code (MISC) global scores, however, the full MISC scoring system was not implemented (Miller, Moyers, Ernst, \& Amrhein, 2003). Intervention fidelity was addressed through training, ongoing supervision, and fidelity measures completed by both participants (on a voluntary basis) and clinicians following each BMI session.

\subsection{Procedure and measures}

Data were collected on alcohol use and alcohol-related consequences at baseline (summer prior to matriculation) and again within two weeks of the first BMI session in the Fall of the participants' freshman year. Follow ups were scheduled at 10-, and 22-months post-baseline. Additionally, session evaluation data were collected immediately after the BMI and booster sessions. For the purposes of this study, the 10 and 22-month follow-ups were employed to examine whether clinician continuity had an effect on alcohol use, associated problems, and session ratings.

Past/lifetime alcohol use-Past and lifetime alcohol use was assessed by asking respondents to indicate whether they had ever consumed more than one alcoholic beverage, and if so had they drank on any one occasion during the past year. An answer of "no" to either question classified the respondent as an 'abstainer' for the purposes of this research.

\section{Daily Drinking Questionnaire (DDQ; Baer, Kivlahan, Blume, McKnight, \&} Marlatt, 2001; Collins, Parks, \& Marlatt, 1985)—The DDQ assesses the number of standard drinks consumed on each day of a typical drinking week. Adding the number of drinks consumed on each day created a summary score of 'drinks per week'.

Heavy episodic drinking-Heavy episodic drinking was assessed for the past two weeks using the criteria of five or more drinks in a row for both men and women consistent with the Monitoring the Future study (Johnston, O’Malley, Bachman, \& Schulenberg, 2007). 
Peak drinking - Past month peak drinking was assessed by a single-item from the Quantity-Frequency Questionnaire (Dimeff, et al., 1999), asking participants to indicate the number of drinks that they consumed on the occasion that they drank the most in the past month.

Drinking game participation-Participation in drinking games was assessed with one item recording the frequency of drinking game participation in the past 30 days.

Alcohol-related consequences-Alcohol-related consequences were assessed with a seventeen-item version of the Young Adult Alcohol Problems Screening Test (YAAPST; Hurlbut \& Sher, 1992). The adapted YAAPST scale assessed past 3-month frequency of alcohol problems for both general consequences (e.g., hangovers, blackouts, driving while intoxicated) and problems presumably more unique to or prevalent in college student populations (e.g., missing class, doing poorly on exams). A severity summary score was created by weighting each problem experienced by the number of times it occurred. In this study, the coefficient alpha for the YAAPST was .81 at baseline and .84 at follow-up.

\section{Student Session Evaluation (Adapted from Project MATCH; Carroll, et al.,} 1998)-Student evaluations were designed to rate participant responses to the BMI session content, interventionist qualities, and session satisfaction. Likert-type scales (1=strongly disagree, $4=$ =strongly agree; $1=$ very dissatisfied, $4=$ =very satisfied) were used. This measure provided three variables including MI-consistent qualities, relevance of information presented, and participant general satisfaction. For this study, three items were combined into a single scale for MI-consistent qualities $(\alpha=87)$. MI-consistent qualities included were rapport ("the interviewer was easy to talk to"), empathy ("the interviewer was warm and understanding"), and self-efficacy ("the interviewer helped me believe I am capable of making my own decisions about drinking"; See Table 1). Relevance was measured by the item: "the information provided was personally relevant to me". Finally, general satisfaction was measured by the item: "in general, how satisfied were you with this session".

\section{Results}

\subsection{Preliminary Analyses}

Baseline equivalence was demonstrated for those who did and did not attend their BMI appointments ( $p s>.10)$, and those who did and did not complete their session evaluations ( $p s>.17)$ on alcohol use, alcohol-related consequences, gender, and age. Demographic information for the sample is provided in Table 1. Attrition analyses revealed no significant differences ( $p s>.05$ ) in baseline assessments corresponding to drinks per week (DDQ), alcohol related consequences (YAAPST), number of heavy drinking episodes, gender, or drinker status between those who had the same clinician and those who had a different clinician across the two BMIs.

Outliers for the dependent variables greater than three standard deviations from the mean were recoded to one value greater than the farthest non-far outlier (Fidell \& Tabachnick, 2003). Furthermore, due to the high variability in case loads among interventionists (Baseline number of sessions per interventionist: $M=23.7$; range = 4-69 sessions; Followup number of sessions per interventionist: $M=23.8$; range $=7-61$ sessions), a formal analysis was precluded examining each interventionist's effect on outcomes. The combination of effects for individual clinicians (when students saw the same clinician) and pairs of clinicians (when students saw two different clinicians) generated by hierarchical linear modeling (using 16 levels of the clinician variable) would create an unwieldy number of iterations, and is beyond the scope of the present research. However, 16 (clinician) $\times 2$ 
(baseline and 22 month follow-up) ANOVA analyses revealed no differences between interventionists for each outcome variable $(p s>.35)$.

\subsection{Outcome Analyses}

To examine group differences at the booster session, a series of hierarchical regression analyses were conducted on each of the eight outcome variables. For each, outcome variables measured at the 22 month follow-up were used as the dependent variables. Supplemental analyses were conducted to examine differences between those who received a combination of PBI and BMI or BMI-only on outcome variables. Results indicated there were no significant differences ( $p s>.38$ ) between those who received the 1) PBI and BMI with the same clinician; 2) BMI-only with the same clinician; 3) PBI and BMI with a different clinician; or 4) BMI-only with a different clinician. Therefore, the BMI-only group and the BMI + PBI group were combined and all included in the present analyses.

The first set of hierarchical regression analyses examined the effect of clinician continuity among drinkers on number of standard drinks consumed in a typical drinking week, heavy episodic drinking, peak drinks, drinking games, and the YAAPST severity score (Table 2). In the first step, we entered the baseline score (centered at 0 ) to evaluate time effects, controlling for regression to the mean. In the second step, group differences were evaluated by entering a dummy-coded variable (Same Clinician vs. Different Clinician). The second set of analyses examined the effect of clinician continuity on MI-consistent qualities (Time $1: M=3.87 ; S D=.36$; Time 2: $M=3.89 ; S D=.37)$, relevance of information presented (Time 1: $M=3.48, S D=.65$; Time 2: $M=3.51, S D=.63$ ), and participant general satisfaction (Time 1: $M=3.79, S D=.45$; Time $2: M=3.84, S D=.37$; Table 3). These analyses followed the same steps as outlined above, except added an additional dummycoded variable to step 2 in order to assess group differences by drinker status (Abstainer vs. Drinker). Additionally, an interaction variable (Clinician Status $\times$ Drinker Status) was added in a third step to see if it significantly improved model fit.

These analyses revealed no group differences for clinician continuity in each of the eight dependent variables. Specifically, there were no significant differences between clinician continuity across time points and daily alcohol use, heavy drinking, peak drinks, drinking games, drinking related consequences, MI-consistent qualities, relevance of information provided, or overall session satisfaction. Furthermore, these analyses revealed that drinker status was not significantly related to MI-consistent qualities, relevance of information, or general session satisfaction. Effect sizes found in this study for clinician continuity were very small $\left(\Delta R^{2}<0.02\right.$; Cohen, 1988) indicating that there was little to no effect of clinician continuity on any of the outcomes of interest. The power of this study to detect a small effect $\left(\Delta R^{2}\right.$ of $\left..02-.04\right)$, was greater than .80 across outcomes.

\section{Discussion}

To our knowledge, this is the first published research study to examine the impact of clinician continuity across two BMI sessions with college students. Specifically, we examined whether clinician continuity across an initial BMI and follow-up booster session affected participant differences in change in alcohol use, associated consequences, and BMI session ratings. On the whole, our findings suggest that a lack of clinician continuity across multiple sessions is not associated with worse alcohol-related outcomes or lower session satisfaction among college students.

Although not directly tested here, we believe that the use of a standardized BMI protocol, as well as extensive training and supervision, may have contributed to the lack of influence of clinician continuity on the observed efficacy of the BMI. Specifically, high ratings of 
therapist qualities such as empathic listening, establishing rapport, and enhancing feelings of self-efficacy were obtained whether participants met with the same or a different clinician (See Table 1). Therefore, in the context of a brief intervention, it is the therapist behaviors, not the therapist him/herself, that may contribute to the efficacy of the intervention. Previous research has indicated that therapeutic alliance and rapport can contribute to therapeutic outcomes (Grencavage \& Norcross, 1990; Horvath \& Bedi, 2002; Kazdin, 2005). In the addictions literature, therapist empathy and high levels of therapist interpersonal skills have been associated with positive outcomes (Miller, Taylor, \& West, 1980; Valle, 1981). More recent research on motivational interviewing has found therapist behaviors consistent with motivational interviewing (e.g., reflective listening) to be associated with client change talk (Glynn \& Moyers, in press; Houck \& Moyers, 2008; Moyers \& Martin, 2006), which in turn is associated with subsequent reductions in substance use (e.g., Moyers \& Martin, 2006; Moyers, Martin, Houck, Christopher, \& Tonigan, 2009). Therefore, the extensive training and supervision may have resulted in a consistency of therapist behaviors that outweighed the assumed benefits of clinician continuity in the context of multiple-session brief motivational interventions. This is not to say that having the same clinician does not matter in all situations. In contrast, many therapies rely and recommend having the same clinician administer all sessions (e.g., prolonged exposure, Foa, Hembree, \& Rothbaum, 2007). Nevertheless, this study suggests there is little risk of hindering session alliance and rapport among college students by using a different therapist at follow-up booster sessions. The importance of having the same clinician may be negated in the context of short-term (two session) therapies or by clinician skills in some contexts (e.g., BMIs with non treatment seeking individuals) perhaps due to the limited amount of therapeutic alliance established in just one session. Therefore, a lack of clinician continuity does not appear to impede treatment outcomes or session ratings.

These findings have implications for the practitioners who work with college students. Specifically, considering universities are typically dependent on limited resources, the ability to utilize interchangeable clinicians to administer two BMI sessions is a practical advantage in a real-world setting. As shown in previous research, MI skills tend to deteriorate overtime and therefore, training and supervision are necessary to conduct effective BMIs (Miller, Yahne, Moyers, Martinez, \& Pirritano, 2004; Moyers, et al., 2008). In fact, this study suggests that when conducting BMIs with college students, comprehensive training and on-going supervision may be the most important factor in maintaining MI-consistent therapist behaviors; therefore cost associated with quality systematic supervision could be worthwhile for university counseling centers.

This study has limitations that could be addressed in future research. First, the sample used in the current research was primarily Caucasian (89\%) and was slightly over-representative of females (57\%). Future research with a more racially and ethnically diverse sample is necessary to examine whether clinician continuity is important across more diverse groups. Given the notion that there are differences in cultural acceptance of the therapeutic process (e.g., Sue \& Zane, 1987; Vasquez, 2007), this is a particularly important future direction. Second, there was a possible "ceiling effect" on the session evaluation forms. Clinician qualities and BMI satisfaction were consistently rated very high across participants leaving little variability to capture meaningful differences. Although these reports may have been accurate reflections of therapist skill, such a "ceiling effect" on BMI evaluations suggests assessment procedures may be enhanced by evaluating a more diverse range of clinical qualities, using a different measurement scale, and/or providing further assurance to participants that the interventionist will not view their responses. Third, benefits of clinician continuity may be more likely observed in selective or indicated intervention trials with larger intervention effects. Specifically, due to the modest outcomes observed in the universal preventive intervention from which the current study emanated, future studies 
should continue to explore the effects of clinician continuity across sessions. Fourth, the student session evaluation is designed to reflect participant responses to BMI session content, general interventionist qualities, and overall session satisfaction. Therefore, the student session evaluation was not a comprehensive MI-specific rating instrument, and future studies could be enhanced by using a more comprehensive measure such as the Motivational Interviewing Skill Code (Miller, Moyers, Ernst, \& Amrhein, 2003) or the Motivational Interviewing Treatment Integrity code (MITI; Moyers et al., 2005). Finally, students were not randomized to receive the same vs. different clinician. However, given the history of high attrition rates among college students to complete even one BMI session (Mastroleo, Turrisi, Carney, Ray, \& Larimer, 2010; Turrisi et al., 2009), the study was conducted using a more naturalistic matching process typically facilitated by college campus administrators who need to maintain flexible scheduling. Student and clinicians were matched across sessions when their schedules allowed. A more definitive evaluation of the impact of clinician continuity would entail randomly assign students to receive the same or a different clinician.

In conclusion, the use of a different clinician across time-points does not appear to have an adverse effect on alcohol use, associated problems, or session evaluations. These results are a further indication of the flexibility and acceptability of BMIs with college students, and suggest that college alcohol programs should primarily focus on training procedures and intervention fidelity.

\section{Acknowledgments}

This work was supported by National Institute on Alcohol Abuse and Alcoholism Grants R01-AA013919-01A1 to Mark Wood, R01-AA015518 to Brian Borsari, and T32-AA07459 to John T.P Hustad. The contents of this manuscript do not represent the views of the Department of Veterans Affairs or the United States Government.

\section{References}

Ackerman SJ, Hilsenroth MJ. A review of therapist charcteristics and techniques positively impacting the therapeutic alliance. Clinical Psychology Review. 2003; 23(1):1-33. [PubMed: 12559992]

Baer JS, Kivlahan DR, Blume AW, McKnight P, Marlatt GA. Brief intervention for heavy-drinking college students: 4-year follow-up and natural history. American Journal of Public Health. 2001; 91(8):1310-1316. [PubMed: 11499124]

Barnett NP, Murphy JG, Colby SM, Monti PM. Efficacy of counselor vs. computer-delivered intervention with mandated college students. Addictive Behaviors. 2007; 32(11):2529-2548. [PubMed: 17707594]

Borsari B, Carey KB. Effects of a brief motivational intervention with college student drinkers. Journal of Consulting and Clinical Psychology. 2000; 68(4):728-733. [PubMed: 10965648]

Borsari B, Carey KB. Two brief alcohol interventions for mandated college students. Psychology of Addictive Behaviors. 2005; 19(3):296-302. [PubMed: 16187809]

Borsari B, Murphy JG, Carey KB. Readiness to change in brief motivational interventions: A requisite condition for drinking reductions? Addictive Behaviors. 2009; 34:232-235. [PubMed: 18990500]

Burke, BL.; Arkowitz, H.; Dunn, C. The efficacy of motivational interviewing: What we know so far. In: Miller, WR.; Rollnick, S., editors. Motivational interviewing: Preparing people for change. 2. New York: Guilford Press; 2002. p. 217-250.

Carroll KM, Connors GJ, Cooney NL, DiClemente CC, Donovan DM, Kadden RR, et al. Internal validity of project MATCH treatments: Discriminability and integrity. Journal of Consulting and Clinical Psychology. 1998; 66(2):290-303. [PubMed: 9583332]

Cohen, J. Statistical Power Analysis for the Behavioral Sciences. 2. Hillsdale, NJ: Erlbaum; 1988.

Collins SE, Carey KB, Sliwinski MJ. Mailed personalized normative feedback as a brief intervention for at-risk college drinkers. Journal of Studies on Alcohol. 2002; 63:559-567. [PubMed: 12380852] 
Collins RL, Parks GA, Marlatt GA. Social determinants of alcohol consumption: The effects of social interaction and model status on the self-administration of alcohol. Journal of Consulting and Clinical Psychology. 1985; 53(2):189-200. [PubMed: 3998247]

Dimeff, LA.; Baer, JS.; Kivlahan, DR.; Marlatt, GA. Brief Alcohol Screening and Intervention for College Students (BASICS): A harm reduction approach. New York, NY US: Guilford Press; 1999.

Dunn C, Deroo L, Rivara FP. The use of brief interventions adapted from motivational interviewing across behavioral domains: A systematic review. Addiction. 2001; 96(12):1725-1742. [PubMed: 11784466]

Fidell, LS.; Tabachnick, BG. Preparatory data analysis. In: Schrinka, J.; Velicer, W., editors. Handbook of psychology: Research methods in psychology. Vol. 2. New York: John Wiley \& Sons; 2003. p. 115-141.

Foa, E.; Hembree, E.; Rothbaum, B. Prolonged exposure therapy for PTSD: Emotional processing of traumatic experiences. New York, NY: Oxford University Press; 2007.

Glynn LH, Moyers TB. Chasing change talk: The clinician's role in evoking client language about change. Journal of Substance Abuse Treatment. (in press).

Grencavage LM, Norcross JC. Where are the commonalities among the therapeutic common factors? Professional Psychology: Research and Practice. 1990; 21:372-378.

Hettema J, Steele J, Miller WR. Motivational interviewing. Annual Review of Clinical Psychology. 2005; 1:91-111.

Horvath, AO.; Bedi, RP. The alliance. In: Norcross, JC., editor. Psychotherapy relationships that work: Therapists' contributions and responsiveness of patients. New York: Oxford University Press; 2002. p. 37-69.

Houck, JM.; Moyers, TB. What you do matters: Therapist influence on client behavior during motivational interviewing sessions. Paper presented at the First International Addiction Summit; 2008.

Hurlbut SC, Sher KJ. Assessing alcohol problems in college students. Journal of American College Health. 1992; 41(2):49-58. [PubMed: 1460173]

Johnston, LD.; O’Malley, PM.; Bachman, JG.; Schulenberg, JE. NIH Publication No. 08-6418. Bethesda, MD: National Institute on Drug Abuse; 2007. Monitoring the Future national results on adolescent drug use: Overview of key findings, 2006; p. 70

Kazdin AE. Treatment outcomes, common factors, and continued neglect of mechanisms of change. Clinical Psychology: Science and Practice. 2005; 12:184-188.

Larimer ME, Cronce JM. Identification, prevention, and treatment: A review of individual-focused strategies to reduce problematic alcohol consumption by college students. Journal of Studies on Alcohol. 2002:148-163.

Larimer ME, Cronce JM. Identification, prevention, and treatment revisited: Individual-focused college drinking prevention strategies 1999-2006. Addictive Behaviors. 2007; 32(11):2439-2468. [PubMed: 17604915]

Lee CS, Longabaugh R, Baird J, Abrantes AM, Borrelli B, Stein LAR, et al. Do patient intervention ratings predict alcohol-related consequences? Addictive Behaviors. 2007; 32(12):3136-3141. [PubMed: 17720325]

Longabaugh R, Woolard RF, Nirenberg TD, Minugh AP, Becker B, Clifford PR, et al. Evaluating the effects of a brief motivational intervention for injured drinkers in the emergency department. Journal of Studies on Alcohol. 2001; 62(6):806-816. [PubMed: 11838918]

Mastroleo NR, Turrisi R, Carney JV, Ray AE, Larimer ME. Examination of post-training supervision of peer counselors in a motivational enhancement intervention to reduce drinking in a sample of heavy-drinking college students. Journal of Substance Abuse Treatment. 2010; 39:289-297. [PubMed: 20673621]

Miller, WR.; Moyers, TB.; Ernst, D.; Amrhein, P. Unpublished manual. 2. University of New Mexico; 2003. Manual for the Motivational Interviewing Skill Code. Available at: http://www.motivationalinterview.org

Miller, WR.; Rollnick, S. Motivational interviewing: Preparing people for change. 2. New York, NY US: Guilford Press; 2002. 
Miller WR, Taylor CA, West JC. Focused versus broad-spectrum behavior therapy for problem drinkers. Journal of Consulting and Clinical Psychology. 1980; 48:590-601. [PubMed: 7410657]

Miller WR, Yahne CE, Moyers TB, Martinez J, Pirritano M. A randomized trial of methods to help clinicians learn motivational interviewing. Journal of Consulting and Clinical Psychology. 2004; 72:1050-1062. [PubMed: 15612851]

Moyers TB, Manuel PG, Wilson PG, Hendrickson SM, Talcott W, Durand P. A randomized trial investigating training in motivational interviewing for behavioural health providers. Behavioural and Cognitive Psychotherapy. 2008; 36:149-162.

Moyers TB, Martin T. Therapist influence on client language during motivational interviewing sessions. Journal of Substance Abuse Treatment. 2006; 30:245-251. [PubMed: 16616169]

Moyers TB, Martin T, Houck JM, Christopher PJ, Tonigan JS. From in- session behaviors to drinking outcomes: A causal chain for motivational interviewing. Journal of Consulting and Clinical Psychology. 2009; 77:1113-1124. [PubMed: 19968387]

Moyers TB, Martin T, Manuel JK, Hendrickson SM, Miller WR. Assessing competence in the use of motivational interviewing. Journal of Substance Abuse Treatment. 2005; 28:19-26. [PubMed: 15723728]

Sue S, Zane N. The role of culture and cultural techniques in psychotherapy: A critique and reformulation. American Psychologist. 1987; 42:37-45. [PubMed: 3565913]

Turrisi R, Larmier ME, Mallett KA, Kilmer JA, Ray AE, Mastroleo NR, et al. A randomized clinical trial evaluating a combined intervention for high-risk students. Journal of Studies on Alcohol and Drugs. 2009; 70:555-567. [PubMed: 19515296]

Valle SK. Interpersonal functioning of alcoholism counselors and treatment outcomes. Journal of Studies on Alcohol. 1981; 42:783-790. [PubMed: 7311537]

Vasquez MJ. Cultural differences and the therapeutic alliance: An evidence based analysis. American Psychologist. 2007; 62:875-885. [PubMed: 18020774]

White HR, Mun EY, Pugh L, Morgan TJ. Long-term effects of brief substance use interventions for mandated college students: Sleeper effects of an in-person personal feedback intervention. Alcoholism: Clinical and Experimental Research. 2007; 31:1380-1391.

Wood MD, Fairlie AM, Fernandez AC, Borsari B, Capone C, Laforge R, Barros R. Brief motivational and parent interventions for college students: A randomized factorial study. Journal of Consulting and Clinical Psychology. 2010; 78:349-361. [PubMed: 20515210] 


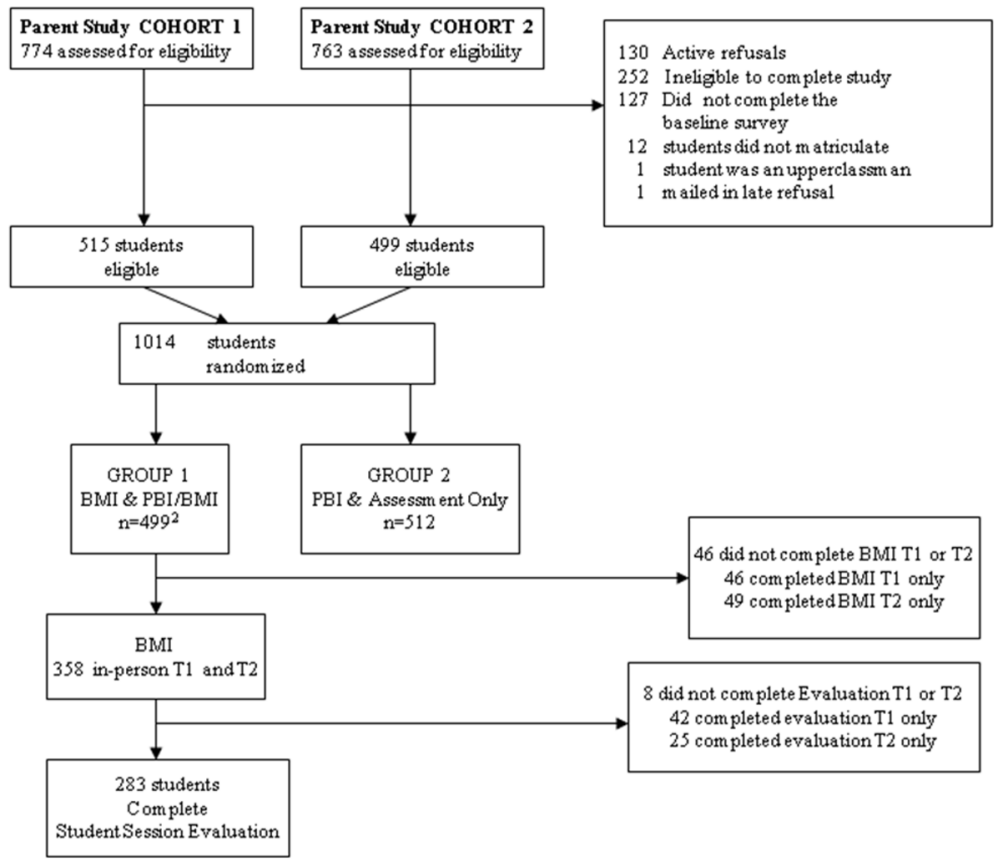

Figure 1.

Attrition Flow Chart 
Table 1

Descriptive Data for Sample (N = 358)

\begin{tabular}{lc}
\hline Demographics & \\
\hline Age & $18.34(.40)$ \\
Female & $205(57.3 \%)$ \\
Caucasian & $318(88.8 \%)$ \\
Percent consumed alcohol past year & $74.6 \%$ \\
Alcohol use (Drinkers only) & \\
Average drinks per week & $10.69(10.29)$ \\
Heavy episodic drinking episodes, past two weeks & $1.59(2.01)$ \\
Peak drinking episode, past month & $6.23(4.46)$ \\
Drinking game participation, past month & $2.21(2.94)$ \\
Alcohol-related problems (Drinkers only) & \\
Number of alcohol consequences & $6.85(8.57)$ \\
Student Session Evaluations for Therapist Qualities & \\
Empathetic listening & $3.90(.39)$ \\
Establishing rapport & $3.90(.39)$ \\
Enhancing self-efficacy & $3.85(.47)$
\end{tabular}

J Subst Abuse Treat. Author manuscript; available in PMC 2012 October 1. 


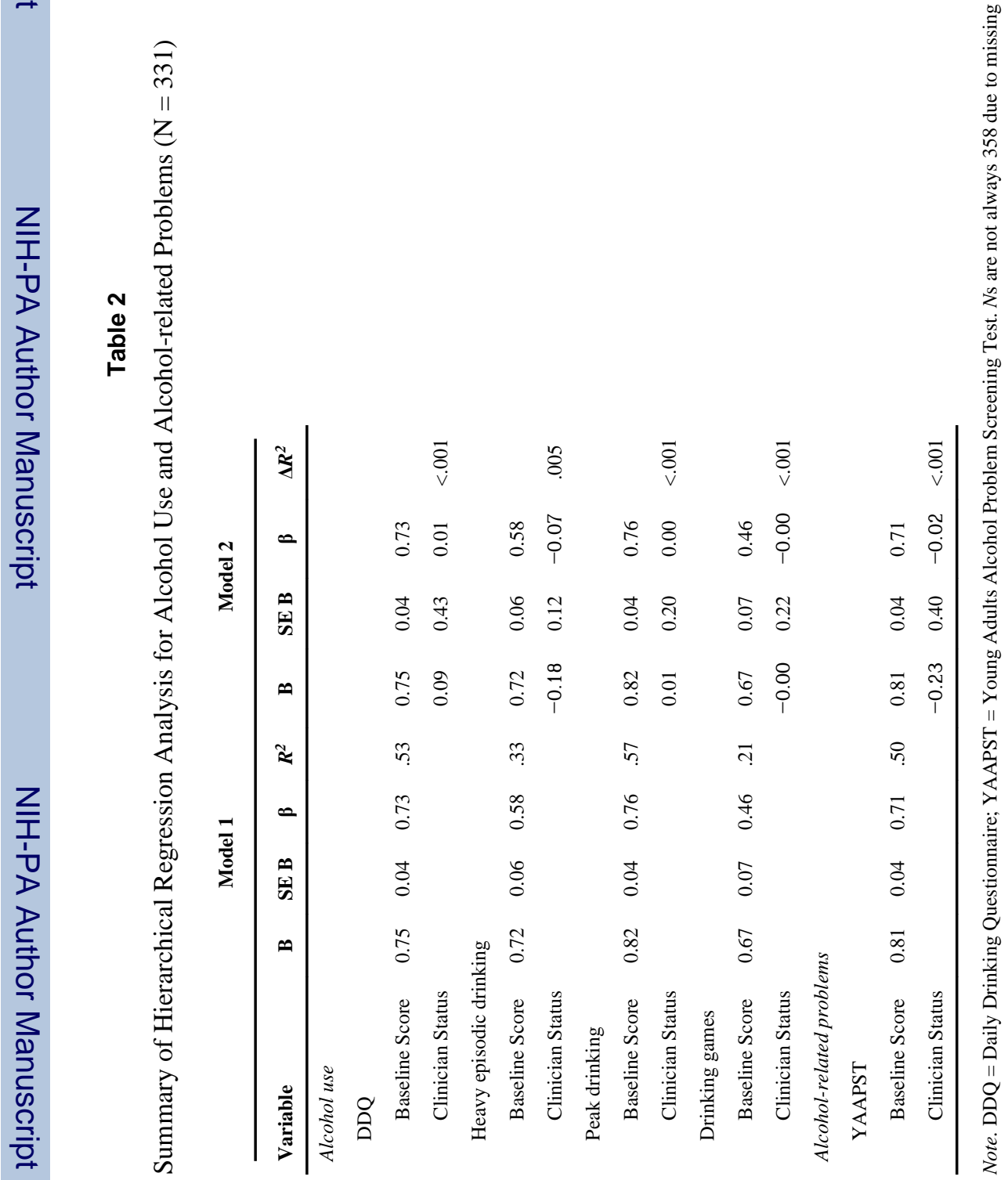




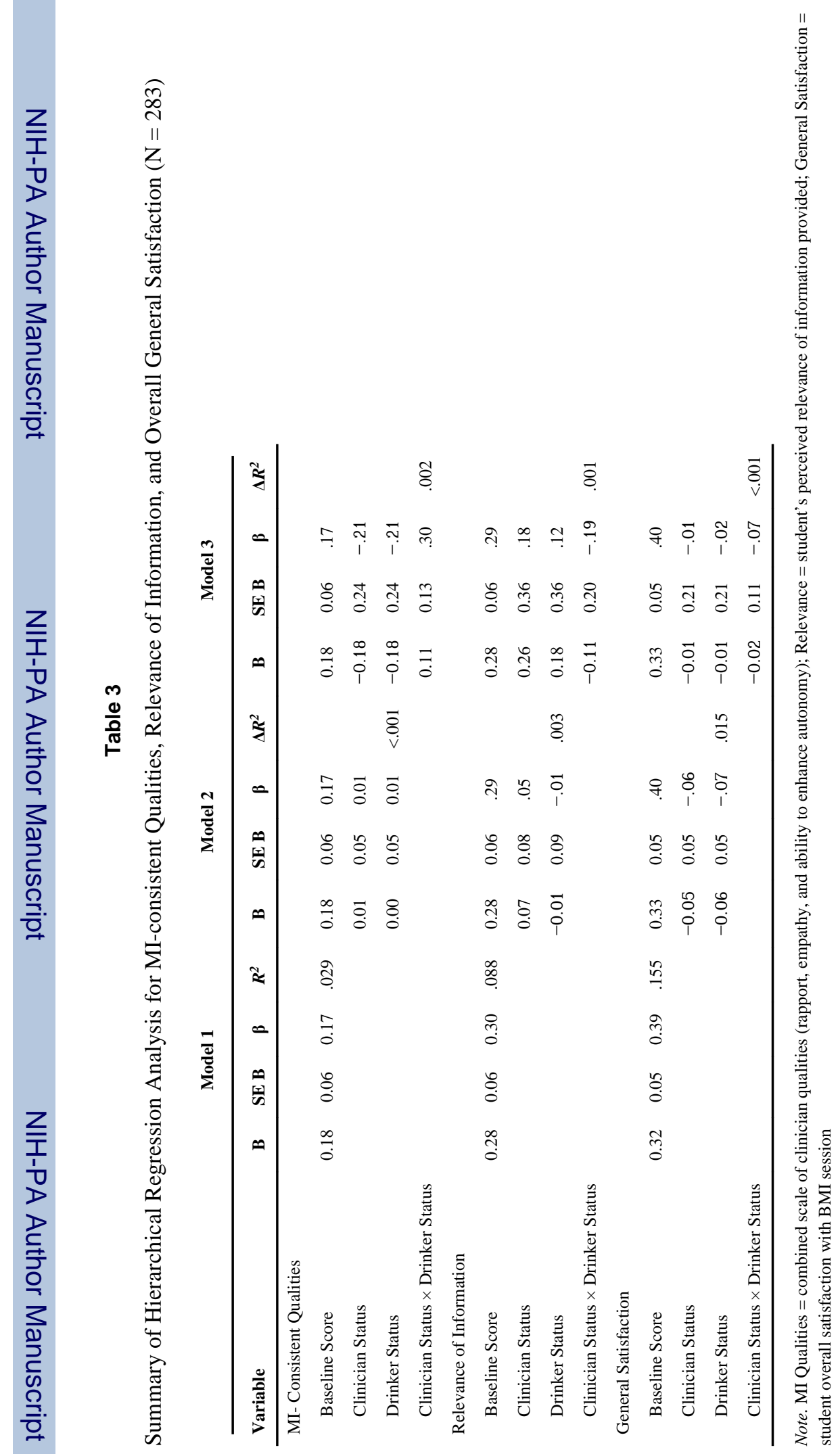

